Check for updates

Cite this: RSC Adv., 2018, 8, 9611

Received 22nd January 2018 Accepted 28th February 2018

DOI: $10.1039 / \mathrm{c} 8 \mathrm{ra00655e}$

rsc.li/rsc-advances

\section{Revealing the in situ NaF generation balance for user-friendly controlled synthesis of sub-10 nm monodisperse low-level $\mathrm{Gd}^{3+}$-doped $\beta-\mathrm{NaYbF}_{4}: \mathrm{Er} \dagger$}

\begin{abstract}
Ji-Wei Shen, (D)* Zhiqing Wang, (D) Xiaoxuan Wei, Jiawei Liu (D) and Yinmao Wei (D)*
Herein, user-friendly control of the synthesis of sub-10 nm hexagonal ( $\beta-$ ) $\mathrm{NaYbF}_{4}$ :Er nanocrystals (NCs) with extremely low-level $\mathrm{Gd}^{3+}$ doping $(0 \%, 10 \mathrm{~mol} \%)$ was achieved. We reveal for the first time that the effective sodium/fluoride levels during the formation of cubic $(\alpha-)$ nuclei are not only controlled by the sodium/fluoride to rare-earth precursor ratios used, but also sensitively restricted by the in situ $\mathrm{NaF}$ generation reaction in a sodium oleate-based solvothermal system. Excessive in situ NaF generation will lead to a respective sodium- and fluoride-deficient environment, delayed $\alpha$-to- $\beta$ transition and larger $\beta$ $\mathrm{NCs}$. Based on these effects, sub-10 nm monodisperse low-level $\mathrm{Gd}^{3+}$-doped $\beta-\mathrm{NaYbF}_{4}$ :Er was obtained with a user-friendly low fluoride dosage by finely balancing this $\mathrm{NaF}$ generation reaction and achieving an intrinsic optimized sodium-fluoride level for NC nucleation. Notably, our work represents the first example where the focus is on the competing in situ $\mathrm{NaF}$ generation reaction and its use for nucleation regulation, as well as for the user-friendly control of the solvothermal synthesis of sub-10 nm $\beta-\mathrm{NaYbF}_{4}$ : Er.
\end{abstract}

\section{Introduction}

The controlled synthesis of multifunctional rare-earth upconversion nanocrystals (UCNCs) is useful for various applications. $^{1-6}$ As a facile strategy, $\mathrm{Gd}^{3+}$ doping could provide synergistic controlled synthesis and multiple functionalities for promising UCNCs obtained via the solvothermal method, especially for $\beta$-NaYbF 4 -based materials. ${ }^{7-10}$ The sodium and fluoride sources in the solvothermal synthesis of $\mathrm{Gd}^{3+}$-doped $\beta$ $\mathrm{NaYbF}_{4}$ are generally supplied by a methanolic solution containing $\mathrm{NaOH}$ and $\mathrm{NH}_{4} \mathrm{~F}$ according to a typical optimal sodium/ fluoride/rare-earth $(\mathrm{Na} / \mathrm{F} / \mathrm{RE})$ ratio of $2.5: 4: 1{ }^{11}$ When the molar doping ratio of $\mathrm{Gd}^{3+}$ reaches as high as $30 \%$ and $40 \%$, the diameter of the $\mathrm{Gd}^{3+}$-doped $\beta-\mathrm{NaYbF}_{4}$ particles is $\sim 20 \mathrm{~nm}$ and $\sim 12 \mathrm{~nm}$, respectively. However, the particle diameters are still as high as $\sim 80 \mathrm{~nm}$ and $\sim 44 \mathrm{~nm}$ when the molar doping ratios of $\mathrm{Gd}^{3+}$ are $10 \%$ and $20 \%$, respectively. ${ }^{9,10}$ It is highly desirable to achieve sub-10 nm $\beta-\mathrm{NaYbF}_{4}$ by using low-level $\mathrm{Gd}^{3+}$ doping (e.g., $0 \%$ or $10 \%$ ), which may be more favorable for high upconversion efficiency.

Insights into the intrinsic UCNC nucleation process should provide new strategies that can overcome the above synthesis control issues. Surveying the literature, we noticed that the previous solvothermal nucleation investigations were mainly

Key Laboratory of Synthetic and Natural Functional Molecule Chemistry of the Ministry of Education, College of Chemistry \& Materials Science, Northwest University, Xi'an 710069, China.E-mail: jiweish@nwu.edu.cn; ymwei@nwu.edu.cn $\dagger$ Electronic supplementary information (ESI) available. See DOI: 10.1039/c8ra00655e focused on regulating the nucleation time, solvent compositions and $\mathrm{Na} / \mathrm{F} / \mathrm{RE}$ ratio from a macroscopic viewpoint. ${ }^{12-14}$ For achieving small-sized $\beta$-UCNCs, sodium oleate (NaOA) used as a sodium source has recently shown its attractively superior properties compared to the most often used $\mathrm{NaOH}$ sodium source. Haase and co-workers pioneered the $\alpha$-nucleus composition versus $\mathrm{Na} / \mathrm{RE}$ ratio investigations and achieved an efficient NaOA-based solvothermal UCNC controlled synthesis strategy. ${ }^{14,15}$ However, the $\mathrm{Na} / \mathrm{RE}$ ratio control in their work was also conducted from the macroscopic point of view. A high $\mathrm{Na} /$ F/RE ratio (e.g., $8: 11: 1)$ that was far in excess of the typical value of $2.5: 4: 1$ was essential for achieving $\alpha$-nuclei with a high sodium content in order to obtain a fast $\alpha$-to- $\beta$ transition and small-sized $\beta$-UCNCs according to their strategy. The formation of sodium-deficient $\alpha$-nuclei under a low $\mathrm{Na} / \mathrm{F} / \mathrm{RE}$ ratio of $2: 5: 1$ was unreasonable to some degree because such a ratio was close to the typical value of $2.5: 4: 1$. The same high Na/F/RE ratio of $8: 11: 1$ was also used for the preparation of sub-10 nm $\beta-\mathrm{NaYbF}_{4}: \mathrm{Tm}$, and reagent-consuming synthesis was seemingly unavoidable for sub- $10 \mathrm{~nm} \beta-\mathrm{NaYbF}_{4} \cdot{ }^{16}$ The intrinsic reasons for the variations in the number of $\beta$-nuclei and the UCNC controlled synthesis effects via variation of the $\mathrm{Na} / \mathrm{F} / \mathrm{RE}$ ratio are still unclear. ${ }^{14,16}$

Fine-tuning of the intrinsic sodium/fluoride levels, as well as their functional morphologies, and the resultant impacts on $\alpha$ nuclei and $\beta$-UCNC formation appear to have been overlooked somewhat in the past. Recently, we achieved small-sized $\beta$ $\mathrm{NaYbF}_{4}: \operatorname{Er}(\sim 11.0 \mathrm{~nm})$ with a size close to $10 \mathrm{~nm}$ by using a NaOAbased solvothermal strategy, but with a low level of sodium and fluoride sources $(\mathrm{NaOA} / \mathrm{F} / \mathrm{RE}, 2.5: 4: 1){ }^{17}$ Such small-sized $\beta$ - 
$\mathrm{NaYbF}_{4}$ :Er was formed due to low in situ $\mathrm{NaOA} / \mathrm{NH}_{4} \mathrm{~F}-$-to-NaF conversion reactivity but enhanced $\mathrm{NH}_{4} \mathrm{~F}$-to-HF decomposition reactivity. We can imagine that the high $\mathrm{Na} / \mathrm{F} / \mathrm{RE}$ ratio (e.g., $8: 11: 1)$-based solvothermal systems described in the literature will provide not only a large amount of in situ generated NaF, but also the user-unfriendly HF. The UCNC nucleation process actually consists of two separate but competing reactions of $\mathrm{NaF}$ generation and $\alpha$-nuclei formation. To date, this in situ $\mathrm{NaF}$ generation reaction has received almost no attention in UCNC controlled synthesis. Our motivation was thus to achieve the userfriendly control of the synthesis of sub-10 nm low-level $\mathrm{Gd}^{3+}$ doped $\beta-\mathrm{NaYbF}_{4}$ : Er by using a low $\mathrm{Na} / \mathrm{F} / \mathrm{RE}$ ratio.

In this work, the definite competing reactions of in situ $\mathrm{NaF}$ generation and $\alpha$-nuclei formation during NaOA-based solvothermal UCNC nucleation were proposed. In contrast with the typical highly skewed $\mathrm{NH}_{4} \mathrm{~F} / \mathrm{RE}$ ratio optimization process (e.g., from $4: 1$ to $8: 1$ ), we revealed for the first time that finetuning of the $\mathrm{NH}_{4} \mathrm{~F} / \mathrm{RE}$ ratio in the vicinity of the stoichiometric value could sensitively balance the competing in situ $\mathrm{NaF}$ generation reaction during NaOA-based solvothermal $\alpha$-nuclei formation and thus achieve user-friendly and reagent-saving control of the synthesis of sub-10 nm low-level $\mathrm{Gd}^{3+}$-doped $\beta$ $\mathrm{NaYbF}_{4}:$ Er by using a very low $\mathrm{Na} / \mathrm{F} / \mathrm{RE}$ ratio.

\section{Experimental}

\section{Materials}

All chemicals used were of at least analytical grade. Oleic acid (HOA, technical grade, 90\%), 1-octadecene (ODE, technical grade, 90\%), sodium oleate and rare-earth acetates were obtained from Sigma-Aldrich (St. Louis, MO, USA). Ammonium fluoride $\left(\mathrm{NH}_{4} \mathrm{~F}, 98 \%\right)$ was purchased from Aladdin Industrial Corporation (Shanghai, China).

\section{Fine tuning of the sodium/fluoride level for NaOA-based} solvothermal controlled synthesis of $\mathrm{NaYbF}_{4}: \operatorname{Er}(2 \mathrm{~mol} \%)$

The synthesis procedures were performed according to the NaOA-based solvothermal strategy for the preparation of UCNCs reported in the literature with some modifications. ${ }^{18} \mathrm{~A}$ mixed solution of HOA/ODE $(3.6 \mathrm{~mL} / 9 \mathrm{~mL})$ was added to a threenecked flask containing the corresponding $0.6 \mathrm{mmol}$ of rareearth acetates. A heating procedure $\left(160{ }^{\circ} \mathrm{C}\right.$ for $\left.30 \mathrm{~min}\right)$ was then performed to obtain rare-earth oleates. On cooling down to $35{ }^{\circ} \mathrm{C}$, NaOA $(1.5 \mathrm{mmol})$ was introduced into this system, followed by stirring at this temperature for $10 \mathrm{~min}$. The designed amount of $\mathrm{NH}_{4} \mathrm{~F}$ dissolved in methanol was then added, followed by stirring at $35{ }^{\circ} \mathrm{C}$ for $30 \mathrm{~min}$ and an increase in the system temperature to $100{ }^{\circ} \mathrm{C}$. The system was cooled down naturally after final UCNC growth at $300{ }^{\circ} \mathrm{C}$.

The as-obtained $\mathrm{NaYbF}_{4}$ :Er was purified and re-dispersed in cyclohexane, and the insoluble component was isolated via centrifugation prior to product characterization. The X-ray powder diffraction (XRD) results indicated that $\mathrm{NaF}$ comprised the majority of the insoluble component. The mass of the insoluble component was thus used to reflect the $\mathrm{NaF}$ content of the system.
To achieve a reagent-saving controlled synthesis strategy for sub-10 nm $\beta-\mathrm{NaYbF}_{4}$ :Er, unless otherwise specified, the $\mathrm{Na} / \mathrm{RE}$ ratio was kept constant at $2.5: 1$ in this work.

\section{Monitoring of the NaF level during solvothermal synthesis}

The solvothermal reactions were stopped by rapid cooling with the help of cool air flow. NaF was collected via washing the centrifugal precipitates with cyclohexane.

\section{$\mathrm{Yb}(\mathrm{OA})_{3}$ preparation}

A mixed solution of $\mathrm{HOA} / \mathrm{ODE}(3.6 \mathrm{~mL} / 9 \mathrm{~mL})$ was added to a $50 \mathrm{~mL}$ flask containing $0.6 \mathrm{mmol}$ of $\mathrm{Yb}\left(\mathrm{CH}_{3} \mathrm{COO}\right)_{3}$. Then, the reaction system was heated at $160{ }^{\circ} \mathrm{C}$ for $30 \mathrm{~min}$ to obtain $\mathrm{Yb}(\mathrm{OA})_{3}$. The as-formed $\mathrm{Yb}(\mathrm{OA})_{3}$ was collected via centrifugation after addition of ethanol (14 $000 \mathrm{rpm}, 5 \mathrm{~min})$.

\section{Monitoring of the nucleation reactions in NaOA-based solvothermal controlled synthesis of $\mathrm{NaYbF}_{4}$ :Er UCNCs}

The NaOA-based solvothermal UCNC synthesis reactions were stopped immediately after the system reached the predetermined temperature, followed by rapid cooling down to room temperature with the help of cool air flow. The precipitate was collected by direct centrifugation or centrifugation after the addition of ethanol. Then, washing procedures were performed by re-dispersing the corresponding precipitate in cyclohexane, followed by the addition of ethanol, and centrifugation.

\section{Seed-mediated epitaxial growth of $\mathrm{NaYF}_{4}$ onto $\beta-\mathrm{NaYbF}_{4}: \mathrm{Gd} /$ Er}

A shell of $\mathrm{NaYF}_{4}$ was grown onto the $\beta-\mathrm{NaYbF}_{4}$ :Gd/Er UCNCs by using procedures based on the conventional seed-mediated epitaxial growth strategy. ${ }^{17}$

\section{Preparation of $\beta-\mathrm{NaYbF}_{4}: \mathrm{Gd} / \mathrm{Er}$ by using a nano-sized NaF- based solvothermal strategy}

The $\beta-\mathrm{NaYbF}_{4}: \mathrm{Gd} / \mathrm{Er}$ was prepared according to the procedure reported in the literature. ${ }^{10}$ Nano-sized NaF was formed by dissolving $\mathrm{NaOH}$ and $\mathrm{NH}_{4} \mathrm{~F}$ into methanol. ${ }^{17}$ Following the literature, nano-sized $\mathrm{NaF}$, instead of $\mathrm{NaOA}$, was used as the source of the sodium supply.

\section{Characterization}

High-resolution transmission electron microscopy (HRTEM), high-angle annular dark-field (HAADF), element mapping and energy-dispersive X-ray analysis (EDXA) were performed using a Tecnai G $^{2}$ F20 microscope (FEI, USA). A D8 ADVANCE X-ray diffractometer (Bruker, Germany) with $\mathrm{Cu} \mathrm{K} \alpha$ radiation $(\lambda=$ $0.15418 \mathrm{~nm}$ ) was used to collect XRD patterns. Upconversion luminescence spectra of the different samples were collected using a RF-5301 spectrofluorometer (Shimadzu, Japan). The samples were excited by a $980 \mathrm{~nm}$ laser source. 


\section{Results and discussion}

Tuning the $\mathrm{NH}_{4} \mathrm{~F} / \mathrm{RE}$ ratio in the vicinity of the stoichiometric value had a significant effect on the NC size in the NaOA-based solvothermal $\mathrm{NaYbF}_{4}: \mathrm{Er}$ synthesis. As reported previously, a conventional stoichiometric ratio of $\mathrm{NH}_{4} \mathrm{~F} / \mathrm{RE}(4: 1)$ provided $\beta-\mathrm{NaYbF}_{4}:$ Er particles with an average diameter of $11.0 \mathrm{~nm} \pm$ $6.5 \%$ by reacting at $300{ }^{\circ} \mathrm{C}$ for $20 \mathrm{~min} .{ }^{17} \mathrm{In}$ this work, we found that a slight increase in the $\mathrm{NH}_{4} \mathrm{~F} / \mathrm{RE}$ ratio from $4: 1$ to $4.25: 1$ provided monodisperse and smaller $\beta-\mathrm{NaYbF}_{4}: \mathrm{Er}$ particles (10.5 nm, Fig. S1 $\mathrm{A}_{\dagger}^{\dagger}$ ), showing an attractive NC diameter decrease effect.

Therefore, fine-tuning of the $\mathrm{NH}_{4} \mathrm{~F} / \mathrm{RE}$ ratio $(4.5: 1,4.75: 1$ and $5: 1$ ) was carried out to explore the possibility of achieving sub-10 nm $\beta-\mathrm{NaYbF}_{4}$ :Er. The NC diameter showed a decreasing and then an increasing tendency with an increased $\mathrm{NH}_{4} \mathrm{~F} / \mathrm{RE}$ ratio, and sub-10 nm narrowly size-distributed $\beta-\mathrm{NaYbF}_{4}: \mathrm{Er}$ $(9.5 \mathrm{~nm} \pm 5.6 \%)$ was obtained at the $\mathrm{NH}_{4} \mathrm{~F} / \mathrm{RE}$ ratio of $4.5: 1$ (Fig. 1A-D, S1 $\dagger$ ). The peak width evolution of the as-prepared $\beta$ $\mathrm{NaYbF}_{4}$ :Er in the XRD pattern results was in agreement with the NC diameter variation tendency (Fig. S2 $\dagger$ ). Encouragingly, the use of precise modification of the $\mathrm{NH}_{4} \mathrm{~F} / \mathrm{RE}$ ratio overcame the issue of controlled synthesis of sub-10 nm monodisperse $\beta$ $\mathrm{NaYbF}_{4}$ :Er. Notably, the optimal $\mathrm{NH}_{4} \mathrm{~F} / \mathrm{RE}$ ratio differed from the conventional optimal ratio of $4: 1$.

To reveal the origin of the above sensitive dependence of the $\mathrm{NaYbF}_{4}:$ Er growth characteristics on the fluoride level, further investigations of the UCNC growth characteristics under different $\mathrm{NaOA} / \mathrm{NH}_{4} \mathrm{~F} / \mathrm{RE}$ ratios were performed (Table 1). An even higher $\mathrm{NH}_{4} \mathrm{~F} / \mathrm{RE}$ ratio of $6: 1$ provided $\alpha$-, $(\alpha+\beta)$ - and $\beta$ $\mathrm{NaYbF}_{4}$ :Er by reacting at $300{ }^{\circ} \mathrm{C}$ for $20 \mathrm{~min}, 30 \mathrm{~min}$ and $45 \mathrm{~min}$, respectively, showing a definite delayed phase transition (Fig. S3 $\uparrow$ ). The diameter of the $\beta-\mathrm{NaYbF}_{4}$ :Er particles obtained

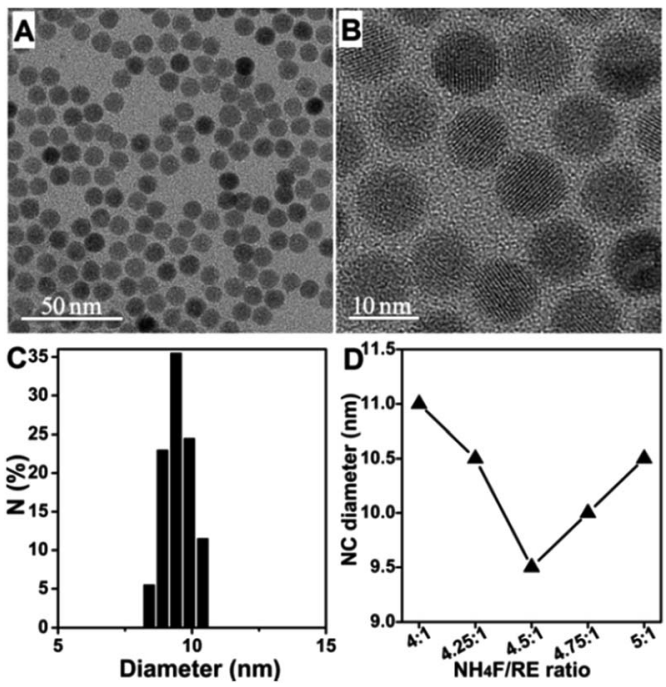

Fig. 1 TEM (A) and HRTEM image (B) of $\beta-\mathrm{NaYbF}_{4}$ : Er prepared by using a $\mathrm{NaOA}$-based solvothermal strategy with an $\mathrm{NH}_{4} \mathrm{~F} / \mathrm{RE}$ ratio of $4.5: 1$ (NC growth was carried out at $300{ }^{\circ} \mathrm{C}$ for $20 \mathrm{~min}$ ). (C) Size distribution of the NCs shown in (A). (D) Plot of $\mathrm{NC}$ size against the $\mathrm{NH}_{4} \mathrm{~F} / \mathrm{RE}$ ratio used for $\beta-\mathrm{NaYbF}_{4}: \mathrm{Er}$.
Table 1 Monitoring of the $\alpha$-to- $\beta$ transition process of $\mathrm{NaYbF}_{4}: \mathrm{Er}$ under different $\mathrm{NaOA} / \mathrm{NH}_{4} \mathrm{~F} / \mathrm{RE}$ ratios

\begin{tabular}{llll}
\hline $\mathrm{NaOA} / \mathrm{NH}_{4} \mathrm{~F} / \mathrm{RE}$ ratio & $20 \mathrm{~min}$ & $30 \mathrm{~min}$ & $45 \mathrm{~min}$ \\
\hline $2.5: 6: 1$ & $\alpha$ & $\alpha+\beta$ & $\beta$ \\
$2.5: 3.5: 1$ & $\alpha$ & $\alpha$ & $\alpha+\beta$ \\
$1.9: 4.5: 1$ & $\alpha+\beta$ & $\beta$ & $\beta$ \\
$3: 6: 1$ & $\alpha$ & $\alpha+\beta$ &
\end{tabular}

by using a higher $\mathrm{NH}_{4} \mathrm{~F} / \mathrm{RE}$ ratio $(6: 1)$ was much larger than that of the particles obtained by using a lower $\mathrm{NH}_{4} \mathrm{~F} / \mathrm{RE}$ ratio (49.6 $\mathrm{nm} \pm 4.5 \%$, Fig. 2A vs. Fig. 1A).

The formation of larger $\beta$-UCNCs under a much higher fluoride level may be attributed to the high surface coverage of $\mathrm{F}^{-}$ions on the NCs according to the theory proposed by Gao et al. ${ }^{19}$ It is possible that a universal and clearer NC nucleation theory could be established to render this $\mathrm{F}^{-}$ion coverage theory compatible with the abovementioned $\alpha$-nuclei sodium abundance theory ${ }^{\mathbf{1 5}}$ and thus supply useful guidelines for solvothermal UCNC controlled synthesis.

The important role of the sodium and fluoride levels in the solvothermal UCNC growth suggested that the in situ NaF generation reaction may have significant effects on the NC nucleation and growth. First, the system NaF levels were monitored after reacting at $300{ }^{\circ} \mathrm{C}$ for $0 \mathrm{~min}$ in the NaOA-based $\mathrm{NaYbF}_{4}: \mathrm{Er}$ synthesis system. Since the $\alpha$-to- $\beta$ transition of $\mathrm{NaYbF}_{4}:$ Er was difficult, $\alpha$-nuclei and NaF were collected this stage. The mass of the collected NaF was $3.9 \mathrm{mg}, 12.2 \mathrm{mg}$ and $25.0 \mathrm{mg}$ when the $\mathrm{NaOA} / \mathrm{NH}_{4} \mathrm{~F} / \mathrm{RE}$ ratio was $2.5: 4: 1$, $2.5: 4.5: 1$ and $2.5: 6: 1$, respectively, showing an obvious tendency of increasing with increased $\mathrm{NH}_{4} \mathrm{~F} / \mathrm{RE}$ ratio (Fig. 2B). Therefore, the actual sodium and fluoride source, which could participate in the $\alpha$-nuclei formation rather than in the inert $\mathrm{NaF}$ generation, supplied effective $\mathrm{NaOA} / \mathrm{NH}_{4} \mathrm{~F} / \mathrm{RE}$ ratios of $2.35: 3.85: 1,2.02: 4.02: 1$ and $1.5: 5: 1$ for the used NaOA/ $\mathrm{NH}_{4} \mathrm{~F} / \mathrm{RE}$ ratios of $2.5: 4: 1,2.5: 4.5: 1$ and $2.5: 6: 1$, respectively (Fig. 2B). A significant amount of sodium/fluoride participated in NaF generation rather than in UCNC nucleation, and we therefore can suggest that the larger $\beta-\mathrm{NaYbF}_{4}: \mathrm{Er}$

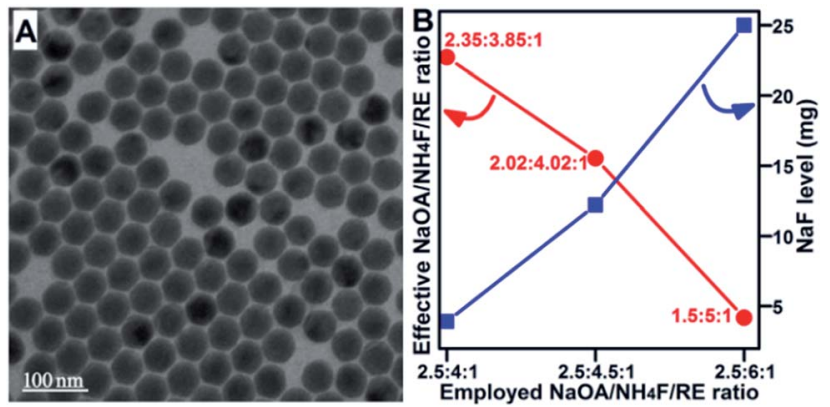

Fig. 2 (A) TEM image of $\beta-\mathrm{NaYbF}_{4}$ :Er prepared by using a $\mathrm{NaOA} /$ $\mathrm{NH}_{4} \mathrm{~F} / \mathrm{RE}$ ratio of $2.5: 6: 1$. (B) Plot of effective $\mathrm{NaOA} / \mathrm{NH}_{4} \mathrm{~F} / \mathrm{RE}$ ratio and system $\mathrm{NaF}$ level versus used $\mathrm{NaOA} / \mathrm{NH}_{4} \mathrm{~F} / \mathrm{RE}$ ratio after reacting at $300{ }^{\circ} \mathrm{C}$ for $0 \mathrm{~min}$ in the $\mathrm{NaOA}$-based solvothermal $\mathrm{NaYbF}_{4}: \mathrm{Er}$ synthesis system. 
particles obtained at low and high $\mathrm{NH}_{4} \mathrm{~F} / \mathrm{RE}$ ratios were due to the formation of fluoride-deficient and sodium-deficient $\alpha$ nuclei formation environments, respectively. The sodiumdeficient environment under a high $\mathrm{NH}_{4} \mathrm{~F} / \mathrm{RE}$ ratio (e.g., $6: 1$ ) should supply sodium-deficient $\alpha$-nuclei, and thus, the formation of larger $\beta$-UCNCs could be supported by the sodium content-dependent $\alpha$-to- $\beta$ transition characteristics of $\alpha$-UCNCs reported in the literature. ${ }^{15}$

Interestingly, sub-10 nm $\beta-\mathrm{NaYbF}_{4}$ : Er was achieved at the effective and nearly stoichiometric $\mathrm{NH}_{4} \mathrm{~F} / \mathrm{RE}$ ratio of $4.02: 1$, which was realized by compensating the system fluoride consumption in the NaF generation reaction via a slight $\mathrm{NH}_{4} \mathrm{~F}$ dosage increase (Fig. 1A and 2B). In fact, the classic NaOA/ $\mathrm{NH}_{4} \mathrm{~F} / \mathrm{RE}$ ratio of $2.5: 4: 1$ supplied a fluoride-deficient nucleation environment for the preparation of $\beta-\mathrm{NaYbF}_{4}: \mathrm{Er}$. The reactivity between sodium and fluoride was strengthened under elevated temperatures, leading to the competing and unfavorable NaF generation reaction during nucleation. The in situ $\mathrm{NaF}$ generation reaction competes with the $\alpha$-nuclei formation reaction in consuming both sodium and fluoride sources during nucleation. Further monitoring of the $\alpha$-nuclei formation process supported the effects of the competing $\mathrm{NaF}$ generation reaction (Fig. 3).

No $\mathrm{NaF}$ could be observed in the optimized $\mathrm{NH}_{4} \mathrm{~F} / \mathrm{RE}$ ratio (4.5 : 1)-based solvothermal $\mathrm{NaYbF}_{4}$ :Er synthesis system (reaction at $160{ }^{\circ} \mathrm{C}, 0 \mathrm{~min}$ ) via direct centrifugation, and only rare-earth oleates and $\alpha$-nuclei were obtained via centrifugation after the addition of ethanol in such a system (Fig. 3A-C, S4†). In contrast, a large amount of precipitate was obtained in a high $\mathrm{NH}_{4} \mathrm{~F} / \mathrm{RE}$ ratio (6:1)-based solvothermal system (reacting at $160{ }^{\circ} \mathrm{C}$, $0 \mathrm{~min}$ ) via direct centrifugation (Fig. S4 $\dagger$ ). The obtained XRD

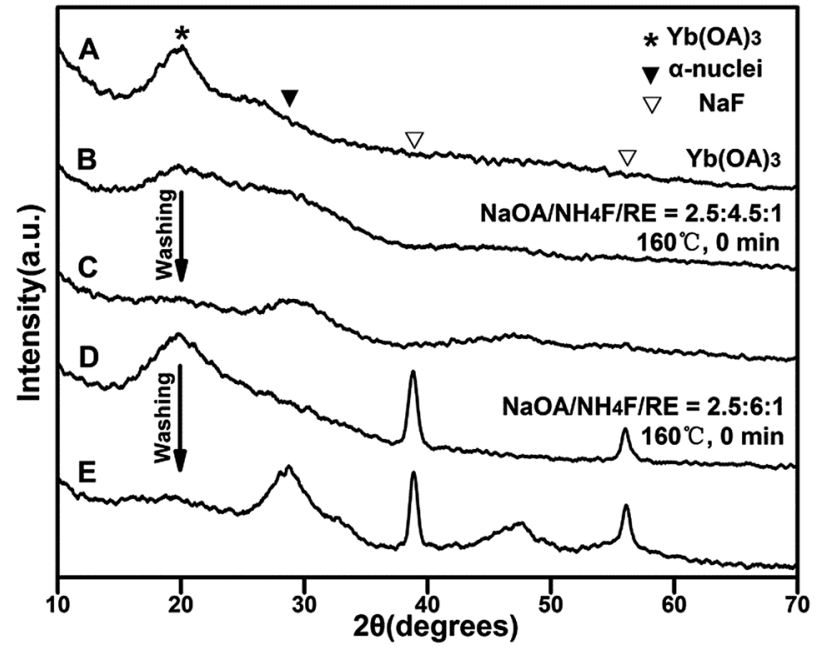

Fig. 3 XRD patterns: $(A) \mathrm{Yb}(\mathrm{OA})_{3}$; $(\mathrm{B})$ the precipitate collected via only a single centrifugation after the addition of ethanol for the $\mathrm{NaOA}$ based $\mathrm{NaYbF}_{4}: \mathrm{Er}$ synthesis system $\left(\mathrm{NaOA} / \mathrm{NH}_{4} \mathrm{~F} / \mathrm{RE}\right.$, $2.5: 4.5: 1$, $160{ }^{\circ} \mathrm{C}, 0 \mathrm{~min}$ ); (C) the product collected after a single washing procedure for the precipitate used in (B); (D) the precipitate collected via direct centrifugation for the $\mathrm{NaOA}$-based $\mathrm{NaYbF}_{4}$ : Er synthesis system ( $\mathrm{NaOA} / \mathrm{NH}_{4} \mathrm{~F} / \mathrm{RE}, 2.5: 6: 1,160{ }^{\circ} \mathrm{C}, 0 \mathrm{~min}$ ); (E) the precipitate collected via a single centrifugation after the addition of ethanol and a single washing procedure for the reaction solution used in (D). patterns indicated that this precipitate was a mixture of rare-earth oleates, NaF and $\alpha$-nuclei (Fig. 3A, D and E). The formation of rare-earth oleates with low dispersity should be due to the excessive surface binding of $\mathrm{F}^{-}$ions on the oleates under a high $\mathrm{NH}_{4} \mathrm{~F} / \mathrm{RE}$ ratio. The excessive surface binding of $\mathrm{F}^{-}$ions onto rareearth oleates not only strengthened the NaF generation reaction, but also retarded the formation of monodisperse $\alpha$-nuclei, as well as the $\alpha$-to- $\beta$ transition, by consuming the active sodium source of the system. These results confirmed the importance of the competing in situ NaF generation reaction for UCNC nucleation.

The effects of the competing NaF generation reaction on UCNC nucleation were also verified by the NC evolution characteristics under fluoride- or sodium-deficient environments. The NaOA/ $\mathrm{NH}_{4} \mathrm{~F} / \mathrm{RE}$ ratio of $2.5: 3.5: 1$ provided $(\alpha+\beta)$ $\mathrm{NaYbF}_{4}$ :Er even after reacting at $300{ }^{\circ} \mathrm{C}$ for $45 \mathrm{~min}$, but large $\beta$ UCNCs had already appeared (Fig. 4A, S5, $\uparrow$ Table 1), indicating that insufficient system fluoride actually retarded the UCNC $\alpha$ to- $\beta$ transition.

To further show the sensitive effect of fluoride level variation on the NC size evolution, we attempted to prepare $\mathrm{NaYbF}_{4}: \mathrm{Er}$ by partial fluoride consumption by slightly elevating the NaOA dosage (NaOA/ $\mathrm{NH}_{4} \mathrm{~F} / \mathrm{RE}, 2.75: 4.5: 1$ ) and strengthening $\mathrm{NaF}$ generation. Approximately $20.6 \mathrm{mg}$ of $\mathrm{NaF}$ was collected in the $\mathrm{NaOA}$-based solvothermal system after reacting at $300{ }^{\circ} \mathrm{C}$ for $0 \mathrm{~min}$. The intrinsic and effective $\mathrm{NaOA} / \mathrm{NH}_{4} \mathrm{~F} / \mathrm{RE}$ ratio for $\alpha$ nuclei formation was thus only $1.93: 3.68: 1$ for the used $\mathrm{NaOA} / \mathrm{NH}_{4} \mathrm{~F} / \mathrm{RE}$ ratio of $2.75: 4.5: 1$, which supplied an obvious fluoride-deficient nucleation environment. Compared to the $\beta$ $\mathrm{NaYbF}_{4}: \mathrm{Er}$ obtained by using the $\mathrm{NaOA} / \mathrm{NH}_{4} \mathrm{~F} / \mathrm{RE}$ ratio of $2.5: 4.5: 1$, the expected much larger $\beta-\mathrm{NaYbF}_{4}: \mathrm{Er}$ particles $(13.4 \mathrm{~nm} \pm 5.9 \%)$ were obtained after reacting at $300{ }^{\circ} \mathrm{C}$ for $20 \mathrm{~min}$ (Fig. 4B).

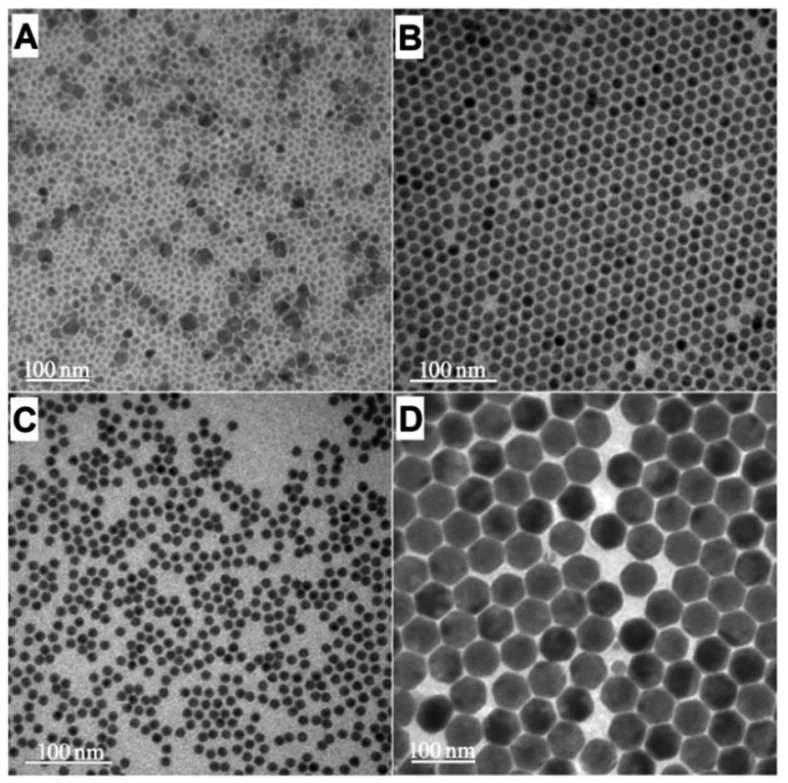

Fig. 4 TEM images of $\mathrm{NaYbF}_{4}$ :Er prepared by using different $\mathrm{NaOA}$ / $\mathrm{NH}_{4}$ F/RE ratios: (A) $2.5: 3.5: 1$; (B) $2.75: 4.5: 1$; (C) $1.9: 4.5: 1$; (D) $3: 6: 1$. The $\mathrm{NC}$ growth reactions were performed at $300^{\circ} \mathrm{C}$ for $(\mathrm{A}$ and D) $45 \mathrm{~min}$ or (B and C) $20 \mathrm{~min}$. 
A slight active sodium deficiency of the system also led to a significantly delayed $\alpha$-to- $\beta$ transition process for $\mathrm{NaYbF}_{4}: \mathrm{Er}$ (Fig. S6, $\dagger$ Table 1). The $\alpha$-to- $\beta$ transition was finished after reacting at $300{ }^{\circ} \mathrm{C}$ for $30 \mathrm{~min}$ rather than $20 \mathrm{~min}$ by using the sodium-deficient $\mathrm{NaOA} / \mathrm{NH}_{4} \mathrm{~F} / \mathrm{RE}$ ratio of $1.9: 4.5: 1$. Such sodium deficiency led to larger-sized $\beta-\mathrm{NaYbF}_{4}: \mathrm{Er}$ particles $(11.5 \mathrm{~nm} \pm 6.3 \%$, Fig. $4 \mathrm{C})$. The $\alpha$-to- $\beta$ transition of $\mathrm{NaYbF}_{4}: \mathrm{Er}$ was still not finished after reacting at $300{ }^{\circ} \mathrm{C}$ for 30 min under an even more severe sodium-deficient environment (NaOA/ $\mathrm{NH}_{4} \mathrm{~F} / \mathrm{RE}, 1.5: 4.5: 1$ ), whereas larger $\beta-\mathrm{NaYbF}_{4}:$ Er particles with an average diameter of $\sim 15.0 \mathrm{~nm}$ had emerged (Fig. S7 $\dagger$ ). These results were in agreement with the hypothesis of sodiumdeficient $\alpha$-nuclei for the formation of larger UCNCs and delayed $\alpha$-to- $\beta$ transition under high $\mathrm{NH}_{4} \mathrm{~F} / \mathrm{RE}$ ratios. ${ }^{15}$ The system sodium and fluoride levels played cooperative roles in regulating the effective sodium-fluoride levels during the nucleation.

The NaF consumption process of the system also supported the important role of the competing NaF generation reaction during the nucleation for the UCNC evolutions. Considerable $\mathrm{NaF}(\sim 15.0 \mathrm{mg})$ still existed even after reacting at $300{ }^{\circ} \mathrm{C}$ for 20 min when using the $\mathrm{NH}_{4} \mathrm{~F} / \mathrm{RE}$ ratio of $6: 1$, while there was no obvious $\mathrm{NaF}$ collected when using a lower $\mathrm{NH}_{4} \mathrm{~F} / \mathrm{RE}$ ratio (e.g., $4: 1,4.5: 1$ ). It should be mentioned that the UCNC growth reaction of $\mathrm{NaF}+\mathrm{ReF}_{3}+\mathrm{m} \beta$-UCNCs (small) $\rightarrow \beta$-UCNCs proposed by Ju and co-worker supported the NaF-dependent $\beta$ UCNC growth characteristics described in our work. ${ }^{20}$ In other words, larger-sized $\beta$-UCNCs would be formed when abundant $\mathrm{NaF}$ existed and was consumed at the NC growth stage.

Another attempt to improve the amount of active sodium source in the solvothermal system by raising the NaOA dosage $\left(\mathrm{NaOA} / \mathrm{NH}_{4} \mathrm{~F} / \mathrm{RE}, 3: 6: 1\right)$ also failed to achieve a better $\alpha$-to$\beta$ transition environment and smaller-sized $\beta-\mathrm{NaYbF}_{4}: \operatorname{Er}(57.3 \pm$ $4.5 \%$, Fig. $4 \mathrm{D}, \mathrm{S} 8, \dagger$ Table 1 ). The mass of NaF collected after reacting at $300{ }^{\circ} \mathrm{C}$ for $20 \mathrm{~min}$ was $\sim 25.5 \mathrm{mg}$, indicating that the newly added NaOA could not supply as effective an active sodium source for NC nucleation because most of it was consumed in promoting the NaF generation reaction by reacting with the active fluoride in the system instead. The active sodium level of the system was constrained by the NaF generation reaction and thus could not be promoted by a simple increase of the dosage.

In summary, the origin and mechanism of the competing $\mathrm{NaF}$ generation and $\alpha$-nuclei formation reactions in the solvothermal $\beta-\mathrm{NaYbF}_{4}$ :Er synthesis could be described as follows. (i) An in situ $\mathrm{NaF}$ generation reaction occurs between the sodium and fluoride sources during the system temperature increase, leading to consumption of both sodium and fluoride in the system. (ii) Since $\alpha$-nuclei are formed by consuming the rare-earth oleates in the system, the sodium and fluoride sources reached the predetermined UCNC growth temperature (e.g., $300{ }^{\circ} \mathrm{C}$ ) first, and the in situ $\mathrm{NaF}$ generation reaction competes with $\alpha$-nuclei formation in the consumption of sodium and fluoride sources during $\alpha$-nucleation. (iii) The effective system sodium-fluoride sources, which participate in $\alpha$-nucleation rather than in in situ NaF generation, should determine the $\alpha$-nucleation efficiency. For instance, the effective $\mathrm{NaOA} / \mathrm{NH}_{4} \mathrm{~F} / \mathrm{RE}$ ratio for $\alpha$-nucleation was only $1.93: 3.68: 1$ for the used $\mathrm{NaOA} / \mathrm{NH}_{4} \mathrm{~F} / \mathrm{RE}$ ratio of $2.75: 4.5: 1$ because the sodium-fluoride sources of the system were consumed in part by the in situ NaF generation reaction, resulting in low $\alpha$-nucleation efficiency because the effective system fluoride level is lower than the necessary stoichiometric value. Briefly, the excessive system sodium source consumes the fluoride source via the in situ $\mathrm{NaF}$ generation reaction and thus leads to fluoride-deficient $\alpha$-nucleation, and vice versa. (iv) The $\alpha$-nucleation efficiency is positively related to the amount of $\beta$-nuclei formed at the UCNC growth temperature and therefore is inversely related to the size of the final $\beta$-NCs.

The findings of the competing in situ NaF generation reaction and $\alpha$-nucleation are also in agreement with the thermodynamically controlled UCNC $\alpha$-to- $\beta$ phase transition mechanism. As is well known, a higher UCNC growth temperature will facilitate the transformation from metastable $\alpha$-nuclei to the thermodynamically stable $\beta$-nuclei. The intrinsic reason for the accelerated $\alpha$-to- $\beta$ phase transition under higher temperature should be the promoted reactivity of the involved ions $\left(\mathrm{Re}^{3+}, \mathrm{Na}^{+}\right.$, and $\left.\mathrm{F}^{-}\right)$and the resultant easier lattice modulation and rearrangement. In other words, the low reactivity of the involved ions would retard the UCNC $\alpha$-to- $\beta$ phase transition. NaF generation balance exists in the solvothermal $\beta$ $\mathrm{NaYbF}_{4}$ :Er synthesis system, including the in situ NaF generation at low temperature $\alpha$-nucleation and NaF consumption at high temperature $\beta$-nucleation/growth. Excessive in situ generated NaF will not only lead to a low $\alpha$-nucleation efficiency, but also to a low reactivity of the $\mathrm{Na}^{+}$and $\mathrm{F}^{-}$ions because of the inertness of NaF. Most of the in situ generated inert NaF would contribute to the later $\beta$-nuclei growth period rather than the initial $\beta$-nuclei formation period, leading to fewer $\beta$-nuclei, delayed $\alpha$-to- $\beta$ transition and larger $\beta$-NCs.

After overcoming the issue of facile control of the synthesis of sub-10 nm monodisperse $\beta-\mathrm{NaYbF}_{4}: \mathrm{Er}$ and revealing the competing reactions during the nucleation process, low-level $\mathrm{Gd}^{3+}$-doped $(10 \%) \beta-\mathrm{NaYbF}_{4}$ :Er was prepared according to this strategy. The diameter of the $\beta-\mathrm{NaYbF}_{4}$ :Er particles decreased from $9.5 \mathrm{~nm} \pm 5.6 \%$ to $5.7 \mathrm{~nm} \pm 7.8 \%$ after doping of $10 \% \mathrm{Gd}^{3+}$, showing an impressive size decrease effect (Fig. 5A). The diameter of $5.7 \mathrm{~nm}$ is in sharp contrast to the much larger diameter of $\mathrm{NaYbF}_{4}: \mathrm{Gd} / \mathrm{Tm}$ particles $(10 / 0.5 \%)(\sim 80 \mathrm{~nm})$ prepared by using a much longer reaction time $(1.5 \mathrm{~h})$ and a nano-sized NaF-based solvothermal strategy. ${ }^{9}$

Monodisperse $\beta-\mathrm{NaYbF}_{4}: \mathrm{Gd} / \mathrm{Er}(10 / 2 \%)$ was also achieved by using an even shorter reaction time of 15 min under the optimized NC synthesis conditions for $9.5 \mathrm{~nm} \beta-\mathrm{NaYbF}_{4}: \operatorname{Er}$ (Fig. 5B and $\mathrm{C}, 5.5 \mathrm{~nm} \pm 6.9 \%$ ). In fact, the NC size distribution was more narrow than that of the NCs prepared using the reaction time of $20 \mathrm{~min}$ as seen from the comparison of Fig. 5A and B, indicating the presence of NC Ostwald-ripening if the solvothermal reaction was not stopped in time. $\mathrm{Gd}^{3+}$ doping resulted in an earlier appearance of the Ostwald-ripening phenomenon for $\beta-\mathrm{NaYbF}_{4}$. Elemental analysis showed that the actual $\mathrm{Gd}^{3+}$-to- $\mathrm{Yb}^{3+}$ ratio in the as-prepared $\beta-\mathrm{NaYbF}_{4}: \mathrm{Gd} / \mathrm{Er}$ $(10 / 2 \%)$ was $\sim 1: 9.2$, very close to the theoretical value $(1: 8.8)$, indicating the successful $\mathrm{Gd}^{3+}$ doping into $\beta-\mathrm{NaYbF}_{4}$ (Fig. $5 \mathrm{D}-\mathrm{F}$, 

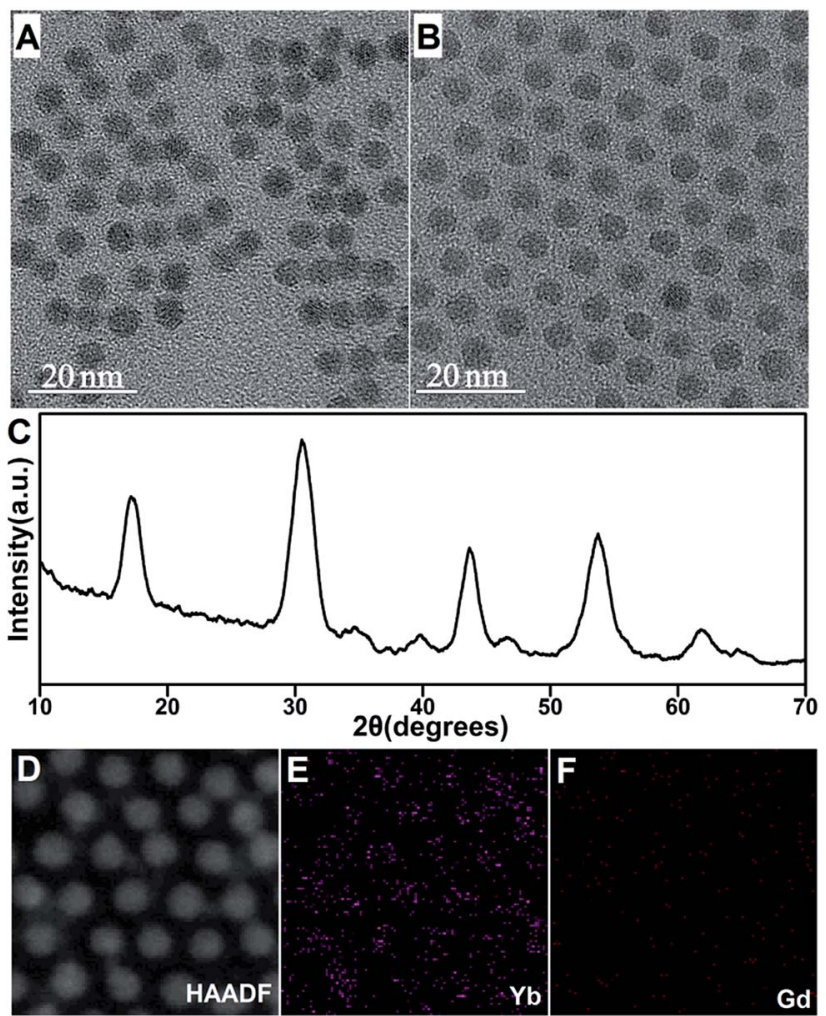

Fig. 5 TEM images of $\beta-\mathrm{NaYbF}_{4}: \mathrm{Gd} / \mathrm{Er}(10 / 2 \%)$ prepared using the optimized $\mathrm{NC}$ synthesis conditions for $9.5 \mathrm{~nm} \beta-\mathrm{NaYbF}_{4}: \mathrm{Er}$ and reacting at $300{ }^{\circ} \mathrm{C}$ for $20 \mathrm{~min}(\mathrm{~A})$ and $15 \mathrm{~min}$ (B). (C) Corresponding XRD pattern of the sample used in (B). (D) HAADF image of randomly selected NCs for the sample used in (B). (E and F) Element maps for the NCs shown in (D).

S9†). These results demonstrated that balancing the competing $\mathrm{NaF}$ generation and $\alpha$-nuclei formation reactions successfully overcame the challenge of the controlled solvothermal synthesis of sub-10 nm low-level Gd ${ }^{3+}$-doped $\beta-\mathrm{NaYbF}_{4}$ :Er.

For control experiments, $\mathrm{NaYbF}_{4}: \mathrm{Gd} / \mathrm{Er} \quad(10 / 2 \%)$ was prepared according to the nano-sized NaF-based solvothermal strategy reported in the literature. ${ }^{10}$ The $\alpha$-to- $\beta$ transition was still not completed after $40 \mathrm{~min}$ of reaction at $300{ }^{\circ} \mathrm{C}$ (Fig. 6A). Pure $\beta$-UCNCs as large as $\sim 70 \mathrm{~nm}$ were achieved after reacting at $300{ }^{\circ} \mathrm{C}$ for $60 \mathrm{~min}$ (Fig. 6B). Moreover, the as-prepared $\beta$ -

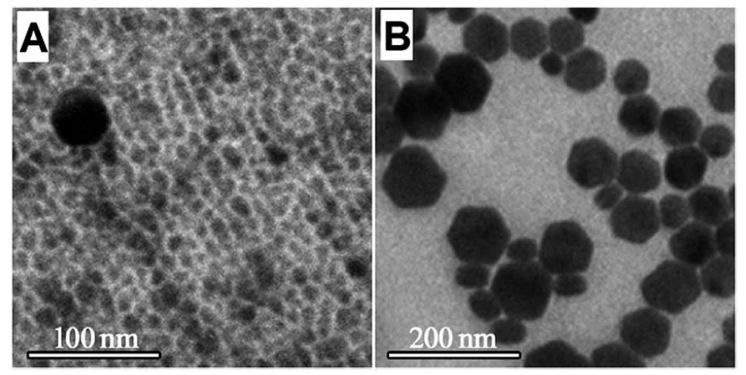

Fig. 6 TEM images: $\mathrm{NaYbF}_{4}: \mathrm{Gd} / \mathrm{Er}(10 / 2 \%)$ prepared by using the nano-sized NaF-based solvothermal strategy and reacting at $300{ }^{\circ} \mathrm{C}$ for $40 \mathrm{~min}(\mathrm{~A})$ and $60 \mathrm{~min}(\mathrm{~B})$.
UCNCs are very non-uniform in morphology. This phenomenon is not caused by the Ostwald-ripening mechanism because the $\alpha$-to- $\beta$ transition has just finished. The $\beta$-nuclei for $\beta$-UCNCs with sharp size differences should form in different nucleation periods, which could be explained by the slow release of the $\mathrm{Na}^{+}$ and $\mathrm{F}^{-}$ions from the inert nano-sized $\mathrm{NaF}$. These comparisons confirmed that low-level $\mathrm{Gd}^{3+}$ doping could not obtain sub$10 \mathrm{~nm} \beta$-UCNCs using the nano-sized NaF-based solvothermal strategy due to ex situ $\mathrm{NaOH} / \mathrm{NH}_{4} \mathrm{~F}$-to-inert NaF conversion. The UCNCs prepared via the nano-sized NaF-based strategy were still too large for bio-applications (Fig. 6B).

Finally, the upconversion intensity of the as-prepared $5.5 \mathrm{~nm}$ $\beta-\mathrm{NaYbF}_{4}: \mathrm{Gd} / \mathrm{Er}(10 / 2 \%)$ was evaluated by comparison to highlevel $(40 \%) \mathrm{Gd}^{3+}$-doped $\beta-\mathrm{NaYbF}_{4}: \mathrm{Er}$, as well as the large-sized $\beta-\mathrm{NaYbF}_{4}: \mathrm{Gd} / \mathrm{Er}(30 / 2 \%)$ with promising upconversion efficiency for practical applications. Similar-sized $\beta-\mathrm{NaYbF}_{4}: \mathrm{Gd} / \mathrm{Er}$ $(40 / 2 \%)(\sim 5.6 \mathrm{~nm})$ was achieved by using the same synthesis procedures as those of the $5.5 \mathrm{~nm} \beta-\mathrm{NaYbF}_{4}: \mathrm{Gd} / \mathrm{Er}(10 / 2 \%)$ (Fig. S10A $\dagger$ ). The low-level $\mathrm{Gd}^{3+}$-doped $\beta-\mathrm{NaYbF}_{4}$ :/Er showed a stronger upconversion intensity than the high-level $\mathrm{Gd}^{3+}$ doped $\mathrm{NaYbF}_{4}$ :/Er, suggesting that the $\mathrm{NaYbF}_{4}$ may be a more efficient upconversion host material than $\mathrm{NaGdF}_{4}$ (Fig. S10D†). Our previous work also supports the conclusion that $\mathrm{NaYbF}_{4}$ is an excellent upconversion host material. ${ }^{17}$ However, the upconversion intensity of the $5.5 \mathrm{~nm} \beta-\mathrm{NaYbF}_{4}: \mathrm{Gd} / \operatorname{Er}(10 / 2 \%)$ is much weaker than that of the large-sized $\beta-\mathrm{NaYbF}_{4}: \mathrm{Gd} / \mathrm{Er}(30 /$ $2 \%$ ) ( $\sim 20 \mathrm{~nm}$, Fig. S10B $\dagger$ ) obtained using the procedure based on the reports in the literature..$^{10}$ In view of the much higher surface-to-volume ratio of the smaller-sized $\beta-\mathrm{NaYbF}_{4}: \mathrm{Gd} / \mathrm{Er}$ and the resultant low upconversion intensity induced by surface quenchers, an optically inert $\mathrm{NaYF}_{4}$ shell was coated onto $\beta-\mathrm{NaYbF}_{4}: \mathrm{Gd} / \mathrm{Er} \quad(10 / 2 \%)$ for upconversion intensity strengthening. The upconversion intensity of the as-obtained small-sized core/shell structured $\quad \beta-\mathrm{NaYbF}_{4}: \operatorname{Gd} / \operatorname{Er}(10 / 2 \%)$ @ $\mathrm{NaYF}_{4}(\sim 9 \mathrm{~nm}$, Fig. S10C $\dagger)$ is comparable to that of the literature-based large-sized $\beta-\mathrm{NaYbF}_{4}: \mathrm{Gd} / \operatorname{Er}(30 / 2 \%)$, indicating the potential of the as-obtained low-level $\mathrm{Gd}^{3+}$-doped $\beta$ $\mathrm{NaYbF}_{4}$ :Er for practical application (Fig. $\mathrm{S}_{0} 0 \mathrm{E} \dagger$ ).

\section{Conclusions}

We showed that the effective sodium-fluoride levels for $\alpha$-nuclei formation were restricted sensitively by the competing in situ $\mathrm{NaF}$ generation reaction in NaOA-based solvothermal UCNC synthesis. The effects of the sodium and fluoride levels on the solvothermal UCNC evolution have been partially neglected in the respective $\mathrm{F}^{-}$ion coverage and the $\alpha$-nuclei sodium abundance theories discussed in the literature. ${ }^{15,19}$ The competing $\mathrm{NaF}$ generation and $\alpha$-nuclei formation reactions were the theoretical basis for both the $\mathrm{F}^{-}$ion coverage and the $\alpha$-nuclei sodium abundance theories. Sub-10 nm monodisperse $\beta$ $\mathrm{NaYbF}_{4}: \operatorname{Er}(9.5 \mathrm{~nm})$ and low-level $\mathrm{Gd}^{3+}$-doped $(10 \mathrm{~mol} \%) \beta$ $\mathrm{NaYbF}_{4}: \operatorname{Er}(5.5 \mathrm{~nm})$ were achieved via facile balancing of the competing in situ NaF generation and $\alpha$-nuclei formation in the absence of high $\mathrm{NaOA}$ and $\mathrm{NH}_{4} \mathrm{~F}$ dosages. Our work supplies new insights and a user-friendly tool for the control of solvothermal UCNC synthesis. 


\section{Conflicts of interest}

There are no conflicts of interest to declare.

\section{Acknowledgements}

This work was supported by the National Natural Science Foundation of China (No. 21505104, 21775121 and 21605122).

\section{References}

1 N. M. Idris, M. K. G. Jayakumar, A. Bansal and Y. Zhang, Chem. Soc. Rev., 2015, 44, 1449-1478.

2 X. G. Liu, C. H. Yan and J. A. Capobianco, Chem. Soc. Rev., 2015, 44, 1299-1301.

3 D. L. Zhou, D. L. Liu, W. Xu, X. Chen, Z. Yin, X. Bai, B. Dong, L. Xu and H. W. Song, Chem. Mater., 2017, 29, 6799-6809.

4 G. Y. Chen, H. L. Qju, P. N. Prasad and X. Y. Chen, Chem. Rev., 2014, 114, 5161-5214.

5 Q. S. Chen, X. J. Xie, B. L. Huang, L. L. Liang, S. Y. Han, Z. G. Yi, Y. Wang, Y. Li, D. Y. Fan, L. Huang and X. G. Liu, Angew. Chem., Int. Ed., 2017, 56, 7605-7609.

6 H. X. Mai, Y. W. Zhang, R. Si, Z. G. Yan, L. D. Sun, L. P. You and C. H. Yan, J. Am. Chem. Soc., 2006, 128, 6426-6436.

7 F. Shi and Y. Zhao, J. Mater. Chem. C, 2014, 2, 2198-2203.

8 Q. Liu, Y. Sun, T. S. Yang, W. Feng, C. G. Li and F. Y. Li, J. Am. Chem. Soc., 2011, 133, 17122-17125.
9 J. A. Damasco, G. Y. Chen, W. Shao, H. Agren, H. Y. Huang, W. T. Song, J. F. Lovell and P. N. Prasad, ACS Appl. Mater. Interfaces, 2014, 6, 13884-13893.

10 Y. L. Liu, K. L. Ai, J. H. Liu, Q. H. Yuan, Y. Y. He and L. H. Lu, Angew. Chem., Int. Ed., 2012, 51, 1437-1442.

11 Z. Q. Li and Y. Zhang, Nanotechnology, 2008, 19, 345606.

12 C. S. Ma, X. X. Xu, F. Wang, Z. G. Zhou, S. H. Wen, D. M. Liu, J. H. Fang, C. I. Lang and D. Y. Jin, J. Phys. Chem. Lett., 2016, 7, 3252-3258.

13 D. D. Li, Q. Y. Shao, Y. Dong and J. Q. Jiang, Chem. Commun., 2014, 50, 15316-15318.

14 T. Rinkel, A. N. Raj, S. Duhnen and M. Haase, Angew. Chem., Int. Ed., 2016, 55, 1164-1167.

15 T. Rinkel, J. Nordmann, A. N. Raj and M. Haase, Nanoscale, 2014, 6, 14523-14530.

16 R. K. Shi, M. A. Ling, X. N. Li, L. Zhang, M. Lu, X. J. Xie, L. Huang and W. Huang, Nanoscale, 2017, 9, 13739-13746.

17 J. W. Shen, Z. Q. Wang, J. W. Liu and H. Li, J. Mater. Chem. C, 2017, 5, 9579-9587.

18 L. Q. Xiong, T. S. Yang, Y. Yang, C. J. Xu and F. Y. Li, Biomaterials, 2010, 31, 7078-7085.

19 C. Y. Liu, Z. Y. Gao, J. F. Zeng, Y. Hou, F. Fang, Y. L. Li, R. R. Qiao, L. Shen, H. Lei, W. S. Yang and M. Y. Gao, ACS Nano, 2013, 7, 7227-7240.

20 J. N. Shan and Y. G. Ju, Nanotechnology, 2009, 20, 275603. 